\title{
FILM REJECT ANALYSIS AS A MEASURE OF QUALITY ASSURANCE: A CASE STUDY OF SOME SELECTED HOSPITALS IN PLATEAU STATE
}

\author{
W. E Mangset ${ }^{1} ه$, K. A Sauri ${ }^{1}$ (D) D. C Langs ${ }^{1}$ \\ ${ }^{1}$ Department of Physics, University of Jos, Plateau State, Nigeria.
}

Received 18 September 2021

Accepted 19 October2021

Published 31 October2021

\section{CorrespondingAuthor}

W.E Mangset, edaci2001@yahoo.com DOI

10.29121/granthaalayah.v9.i10.2021 .4288

Funding: This research received no specific grant from any funding agency in the public, commercial, or not-for-profit sectors.

Copyright: (C) 2021 The Author(s). This is an open access article distributed under the terms of the Creative Commons Attribution License, which permits unrestricted use, distribution, and reproduction in any medium, provided the original author and source are credited.

\section{ABSTRACT}

Film reject analysis is a planned and systematic action necessary to provide adequate confidence that a product or service will satisfy the given requirement for quality of image or radiographs. In this research work, reject film analysis as a quality assurance element was carried out in three selected hospitals in Plateau state, Nigeria for different rejected film sizes for twelve months, from December, 2018- December, 2019. Rejected radiographs were collected, analyzed and categorized based on body parts such as chest, skull, knee, lumbar sacral, shoulder, neck, femur Over exposure, Under exposure, Poor processing, Poor positioning, Wrong placing of anatomical marker, Fog, Artifact and Multiple exposure. The three studied hospitals (selected by convenience), H1, H2, and H3 are located in Jos and environs. From this study, it was observed that the anatomical part mostly rejected was the chest and the highest reason for the rejected radiographs was Under exposure. The reject rates of Hospitals H1, H2, and H3 were found to be 8.85\%, $6.65 \%$ and $5.6 \%$ respectively which were above the World Health Organization (WHO) but within the Conference of Radiation Control Program Directorate (CRCPD) recommended permissible values of $5 \%$ and $(5-10 \%)$ respectively. The findings imply that patients might have been exposed to avoidable radiation doses.

Keywords: X-Ray, Rejected Films, Quality Assurance, Over Exposure, Under Exposure

\section{INTRODUCTION}

$\mathrm{X}$-ray is one of the important diagnostic modalities being used worldwide in the health care service despite being associated with some radiation exposure to the patients Joseph et al. (2015). The discovery of X-ray has proven to be beneficial of which these benefits have been utilized for therapeutic purposes and medical diagnosis. X-rays are known to cause malignance, skin damage and other adverse effects because it causes ionization of molecules in the body tissues and this among other hazards is known to cause cancer and other malignance. Thus, it is mandatory and essential to reduce the radiation dose to patients in diagnostic radiology to the barest minimum Watkinson et al. (1984). A reject image in radiography is an undiagnostic image, as it does not provide the necessary information to aid clinical diagnosis due to its poor quality. Film reject analysis is a planned and systematic action necessary to provide adequate confidence that a product or service will satisfy the given requirement for quality of image or radiographs. The objectives of film reject analysis is to minimize patients' exposure, cost reduction, better image quality, identifying main errors causing film reject, and providing information for teaching and research. 
International Commission on Radiation Protection (ICRP) recommends that medical exposure should be kept as low as reasonably achievable considering economic and social factors (ALARA) and one way of achieving this is through film reject analysis. The aim of radiography is to obtain images which are adequate for clinical purposes with minimum radiation dose to patient. The Conference of Radiographic Control Program Directorate (CRCPD's) committee on Quality Assurance (QA) recommends a higher reject rate of 10\% Joseph et al. (2015).

The World Health Organization (WHO) defined Quality Assurance (QA) as an organized effort by the staff operating a diagnostic facility to ensure that diagnostic images produced by the facility are of high quality so that they consistently provide diagnostic information at the lowest possible cost and with the least possible patient exposure to radiation. Film reject analysis is an essential part of QA in any large Xray department. Firstly, it will indicate weak areas of radiographic and radiological practice in the department, secondly, reject analysis will enable one to note any improvement after quality assurance measures have been put into practice Teferi et al. (2010).

\section{MATERIALS AND METHOD}

The materials used in this study were radiographs (both good and rejected radiographs) and Viewing box. Rejected radiographs consisting of both adults and pediatrics radiographs were collected from three different hospitals in Jos, Plateau State between December 2018 and December 2019. The rejected radiographs consisted of the basic x-ray projections (Antero-Posterior (AP), Posterior-Anterior (PA), and Lateral). The films were assessed on a viewing box and under similar conditions of room light and temperature. Rejected radiograph were analyzed and categorized based on body parts that included; chest, skull, knee, lumbar sacral, shoulder, neck, femur and pelvis. The reasons for rejection were categorized as: over exposure, under exposure, poor processing, poor positioning, wrong placing of anatomical marker, fog, artifact and multiple exposures. The studied Hospitals (selected by convenience) were: Na Allah Nakowa Hospital, H1, General Hospital Mangu, H2, Plateau state Hospital, Jos, and H3.

\section{Reject rate}

The reject rate for each hospital respectively was calculated by the formula below Joseph et al. (2015),

$$
\text { Reject rate }(\%)=\frac{\text { Number of re jected films }}{\text { total number of films used }} \times 100 \%
$$
et al. (2010).

\section{RESULTS AND DISCUSSION HOSPITAL H1}

A total of 1379 films were used in the radiation facility from December 2018 to December 2019. 122 were rejected films. The results are shown in the tables and figure below;

\begin{tabular}{|ccc|}
\hline \multicolumn{3}{c|}{ Table 1 Anatomical Parts of Rejected films } \\
\hline ANATOMICAL PART & NUMBER OF REJECT FILMS & PERCENTAGE \% \\
\hline Chest & 53 & 43.44 \\
Skull & 7 & 5.74 \\
\hline Knee & 21 & 17.21 \\
\hline
\end{tabular}




\begin{tabular}{|ccc|}
\hline Lumbar sacral & 5 & 4.1 \\
\hline Shoulder & 7 & 5.74 \\
\hline Neck & 4 & 3.27 \\
\hline Femur & 13 & 10.66 \\
\hline Pelvis & 7 & 5.74 \\
\hline Abdomen & 5 & 4.1 \\
\hline Total & 122 & 100 \\
\hline
\end{tabular}

Table 2 Reasons for Rejected films for Hospital H1

\begin{tabular}{|ccc|}
\hline REASON OF REJECT & NUMBER OF REJECT FILMS & PERCENTAGE \% \\
\hline Over exposure & 31 & 25.41 \\
\hline Under exposure & 46 & 37.7 \\
\hline Poor processing & 13 & 10.66 \\
\hline Poor positioning & 11 & 9.02 \\
\hline Wrong placing of marker & 6 & 4.92 \\
\hline Fog & 8 & 6.55 \\
\hline Artifact & 7 & 5.74 \\
\hline Multiple exposure & - & - \\
\hline Total & 122 & 100 \\
\hline
\end{tabular}

\section{HOSPITAL H2}

A total of 842 films were used in the radiation facility from December 2018 to December 2019. 56 were rejected films. The reject film rate for hospital $\mathrm{H} 2$ is $6.65 \%$. The results are shown in the tables below

\begin{tabular}{|ccc|}
\hline \multicolumn{3}{|c|}{ Table 3 Anatomical Parts of Rejected films for Hospital H2 } \\
\hline ANATOMICAL PART & NUMBER OF REJECT FILMS & PERCENTAGE \% \\
\hline Chest & 20 & 35.71 \\
\hline Skull & 3 & 5.36 \\
\hline Knee & 2 & 3.57 \\
\hline Lumbar sacral & 13 & 23.21 \\
\hline Shoulder & 3 & 5.36 \\
\hline Neck & 3 & 5.36 \\
\hline Femur & 2 & 3.57 \\
\hline Pelvis & 8 & 14.29 \\
\hline Abdomen & 2 & 3.57 \\
\hline Total & 56 & 100 \\
\hline
\end{tabular}

Table 4 Reasons for Rejected films

\begin{tabular}{|ccc|}
\hline REASON OF REJECT & NUMBER OF REJECT FILMS & PERCENTAGE \% \\
\hline Over exposure & 8 & 14.29 \\
\hline Under exposure & 17 & 30.35 \\
\hline Poor processing & 13 & 23.21 \\
\hline Poor positioning & 12 & 21.43 \\
\hline Wrong placing of marker & 3 & 5.36 \\
\hline Fog & - & - \\
\hline Artifact & 3 & 5.36 \\
\hline Multiple exposure & - & - \\
\hline
\end{tabular}




\section{Total}

56

100

\section{HOSPITAL H3}

A total of 1411 films were used in the radiation facility from December 2018 to December 2019. 79 were rejected films. Hospital H3 has a reject film rate of 5.60\%. The results are shown in the tables below

\begin{tabular}{|lcc}
\hline \multicolumn{2}{l}{ Table 5 Anatomical Parts of Rejected films } & \\
\hline ANATOMICAL PART & NUMBER OF REJECT FILMS & PERCENTAGE \% \\
\hline Chest & 20 & 25.32 \\
\hline Skull & 6 & 7.59 \\
Knee & 4 & 5.06 \\
\hline Lumbar sacral & 12 & 15.2 \\
Shoulder & 8 & 10.13 \\
Neck & 8 & 10.13 \\
Femur & 5 & 6.33 \\
\hline Pelvis & 6 & 7.59 \\
\hline Abdomen & 4 & 5.06 \\
\hline Specials (HSGs) & 6 & 7.59 \\
Total & 79 & 100 \\
\hline
\end{tabular}

Table 6 Reasons of Rejected films

\begin{tabular}{|lcc}
\hline REASON OF REJECT & NUMBER OF REJECT FILMS & PERCENTAGE \% \\
\hline Over exposure & 13 & 16.46 \\
\hline Under exposure & 25 & 31.65 \\
Poor processing & 12 & 15.19 \\
\hline Poor positioning & 17 & 21.52 \\
\hline Wrong placing of marker & 4 & 5.06 \\
\hline Fog & 3 & 3.8 \\
Artifact & 5 & 6.32 \\
\hline Multiple exposure & - & - \\
\hline Total & 79 & 100 \\
\hline
\end{tabular}

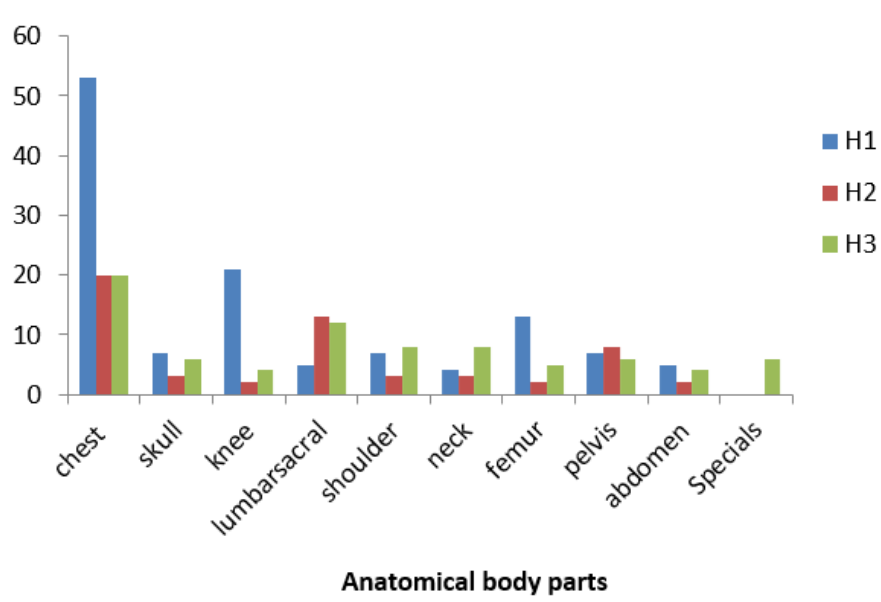

Figure 1 The Comparison of Rejected films based on Anatomical body Parts for the Hospitals 


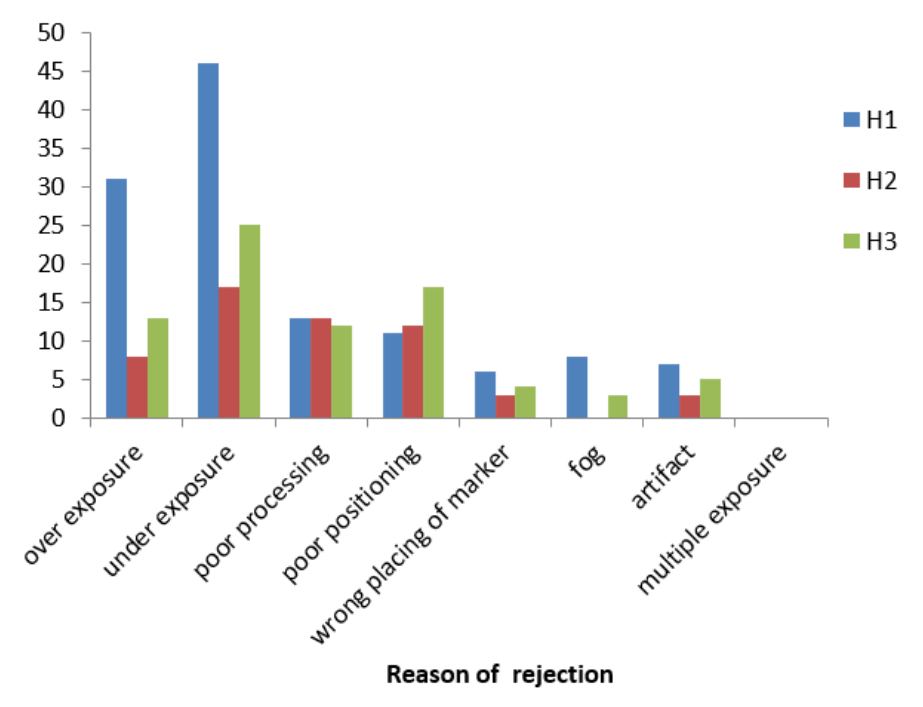

Figure 2 The Comparison Reasons of Rejected films for the Hospitals

Figure 1 shows that the highest anatomical part rejected is the chest and Figure 2 shows also the highest reason for rejection of radiographs was under- exposure and the least reason for the film reject was wrong placing of anatomical marker in Hospital H1 which could either be due to operator's technical limitation, or machine fault. The reject film rate of $\mathrm{H} 1$ was $8.85 \%$. Study of Charlene et al. (2018) shows that under exposure recorded the highest rate after positioning and chest as the highest anatomical part rejected. Figure 3 also shows the highest anatomical part and the least as chest and abdomen respectively, figure 4 shows the highest reason for rejected films was underexposure and the reject film rate for Hospital $\mathrm{H} 2$ was $6.65 \%$. The reject film rate for Hospital $\mathrm{H} 3$ is $5.6 \%$ with the chest as the highest anatomical part rejected and abdomen and knee as the least anatomical part of the rejected radiographs as seen above in figure 5. Figure 6, shows also the highest reason and least reasons of rejected radiographs was underexposure and fog respectively as seen above in figure 6 for Hospital H3. Finding of this study agrees with the study of Jwanbot et al. (2017) which shows that the highest reject radiographs to be chest (anatomical part) with under exposure as being the major cause of rejection.

Other studies disagree with the results of this study as observed that under exposure was a major cause of rejection of radiographs. Banahene et al. (2017), Nwobi et al. (2011), in their studies reported that over exposure and positioning error were the most occurring reasons for rejection of radiographs. Dunn and Rogers (1998) reported in their study also that patient positioning was the major cause of film reject

The reject rate of Hospital H1, H2, H3 was found to be 8.85\%, 6.65\% and 5.6\% respectively which were above the World Health Organization and within the Conference of Radiation Control Program Directorate (CRCPD) recommended permissible of $5 \%$ and (5-10\%) respectively.

\section{CONCLUSION}

From this study, we observed that the anatomical part mostly rejected was the chest and the highest reason of rejected radiographs was under exposure. The reject rate of Hospital $\mathrm{H} 1, \mathrm{H} 2, \mathrm{H} 3$ were found to be $8.85 \%, 6.65 \%$ and $5.6 \%$ respectively which are above the World Health Organization recommended limit but within the 
Conference of Radiation Control Program Directorate (CRCPD) recommended limit of $5 \%$ and $(5-10 \%)$ respectively. The findings imply that patients might have been exposed to avoidable radiation doses.

\section{ACKNOWLEDGEMENT}

The researchers are grateful to the management staff of the studied Hospitals for the permissions to carry out the study and the cooperation enjoyed in the course of the study.

\section{REFERENCES}

Banahene J. O., Darko E.O., Hersferd F., Addison E. K. \&Asiriji J. O (2017); Film Reject Analysis and Image Quality in Diagnostic Radiology Department of a Teaching Hospital in Ghana. Journal of Radiation Research and Applied Sciences.(7): $\quad 589-594 . \quad$ Retrieved from https://doi.org/10.1016/j.jrras.2014.09.012

Charlene B., Christine D., Edwin R. D., Mondijala A., \& Caroline N. (2018); The cause of reject images in radiology department at a state hospital in Windhoek, Namibia. The south African Radiographer 56(1); 35-39. Retrieved from https://journals.co.za/doi/pdf/10.10520/EJC-ed5d71aed

Dunn, M. A, \& Rogers, A. T. (1998); X-ray film reject analysis as quality indicator. Radiography, 29-31. Retrieved from https://doi.org/10.1016/S10788174(98)80027-8

Joseph D. Z., Mohammad S., Abubakar M., Goni M., \& Otopa R (2015); Film reject analysis in radiology department of a teaching hospital in Northern-eastern. Nigeria. Nigeria Journal of Medial Imaging and Radiation Therapy.4(1);2127

Jwanbot D.I, Sirisena U.A.I, Akpolile F.D,Tangtur T.S \& Nkop P.M (2017); Analysis of reject radiographic films as quality assurance element in diagnostic radiology. International Journal of Innovative Healthcare Research 5(1);2430

Nwobi I.C., Agwu K. K.,Garba I. \& James P (2011); Analysis of Rejected Films At The University of Maiduguri Teaching Hospital (UMTH). Nigerian Journal of Medical Imaging And Radiation Therapy.1(2): 23-26.

Teferi S., Zawdeneh D., Admassie D., Nigatu B. \& Kebeta K (2010); X-ray Film Reject Rate Analysis at Eight Selected Government Hospitals in Addis Ababa, Ethiopia. Ethiopia J. Health Development. 26(1): 54-59. Retrieved from https://www.ajol.info/index.php/ejhd/article/view/83829

Watkinson, S., Moores, B. M., \& Hill, S. J. (1984). Reject analysis: its role in quality assurance. Radiography, 50(593), 189-194. Retrieved from https://europepmc.org/article/med/6484122 